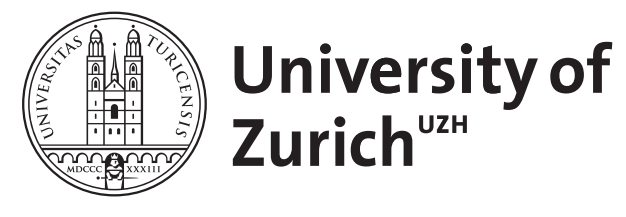

\title{
Corpus-based approaches to World Englishes
}

\author{
Hundt, Marianne
}

\begin{abstract}
The chapter provides an overview of the developments in synchronic and diachronic corpuslinguistic research into World Englishes (WE), detailing methodological concerns such as sampling frames, representativeness, corpus size, and statistical modelling on the one hand and the broadening scope of corpus-based research from ENL to ESL and EFL varieties on the other hand. It also surveys areas in which corpus-evidence has been applied in the study of WE (e.g. as a testing bed for models of WEs, for the study of language contact, typology and change or as a source of evidence for sociolinguistic and pragmatic variation), providing ample illustration from seminal research papers and recent studies in the field.
\end{abstract}

DOI: https://doi.org/10.1017/9781108349406.022

Posted at the Zurich Open Repository and Archive, University of Zurich

ZORA URL: https://doi.org/10.5167/uzh-179333

Book Section

Published Version

Originally published at:

Hundt, Marianne (2020). Corpus-based approaches to World Englishes. In: Schreier, Daniel; Hundt, Marianne; Schneider, Edgar. The Cambridge Handbook of World Englishes. Cambridge: Cambridge University Press, 506-533.

DOI: https://doi.org/10.1017/9781108349406.022 


\section{2 \\ Corpus-Based \\ Approaches to World Englishes}

Marianne Hundt

\subsection{Introduction}

Research into World Englishes (WEs) draws on various methods, including linguists' intuitions, elicitation experiments, and anecdotal evidence. When it comes to describing and modeling variation in WEs, data from corpora add important detail. Bao and Wee (1999), for instance, report that Singapore English (SingE) has a nativized (adversative) passive construction combining a loan word from Malay (kena, "to strike/suffer") with a past participle:

(1) I mean they're like there is guy who must be about sixty over then always kena teased by this other guy uhm. (ICE-SG, S1A-079)

When we look at corpus evidence from the Singapore component of the International Corpus of English (ICE) we see that this construction is extremely rare in standard SingE, even in spontaneous spoken usage, where the bepassive and the get-passive prevail (Bao 2010: 801-804). ${ }^{1}$

Almost from the very beginning, corpus-based research on the English language has taken regional variation into account: the first standard reference corpus for English - a one-million-word sample of printed American English (AmE) text extracts from 1961 - was soon to be followed by a matching corpus of British English (BrE). These two corpora - named Brown (AmE) and Lancaster-Oslo-Bergen (BrE) corpus after the universities involved in their compilation - were then followed by corpora that made use of more or less identical sampling criteria to enable usage-based investigation of Australian (AusE), New Zealand (NZE), and Indian English (IndE). Since its beginnings in the 1960s, when computer storage capacity was still very limited and usage-based research went against the

\footnotetext{
1 Bao (2010: 802) reports a total of six instances of the kena-passive in ICE-SG, whereas the publicly available version of the corpus only yields a total of two instances (the two examples quoted by Bao 2010).
} 
dominant approach in the field (i.e. introspection-based grammaticality judgments), English corpus linguistics has come a long way. This chapter looks at developments in corpus linguistics in the WEs context in various subdisciplines, including both synchronic and diachronic approaches.

Generally speaking, Biber et al. (1998: 4) characterize the corpus-based approach by the following key components:

- it is empirical, analysing the actual patterns of use in natural texts;

- it utilizes a large and principled collection of natural texts, known as a "corpus," as the basis for analysis;

- it makes extensive use of computers for analysis, using both automatic and interactive techniques;

- it depends on both quantitative and qualitative analytical techniques.

As this chapter will show, studies of WEs have made use of corpus evidence in the ways described by Biber et al. (1998). They have been used to describe variation within and across WEs, that is, for both intra- and intervarietal research. Occasionally they limit their methodology to qualitative description. This is not necessarily a shortcoming of such studies as not all theoretical perspectives on WEs might be amenable to statistical modeling of variation in the first place. Also, what exactly constitutes a corpus might need some discussion. Thus, Section 22.2 will introduce different types of corpora and approaches to corpus compilation. Corpus-based research into WEs has progressed from a focus on first-language varieties to institutionalized secondlanguage varieties and learner varieties of English, as the overview of synchronic corpora in Section 22.3 shows. As corpus linguistics is first and foremost just a methodology, Section 22.4 looks into the application of synchronic corpus evidence in WEs research. This is followed by an overview of studies with a focus on variation and change in Section 22.5. The outlook in the final section considers open challenges, research lacunae, and possible future developments in corpus-based studies of WEs. The focus of this chapter is on studies based on publicly available corpora.

\subsection{From Standard Reference Corpora to Web-Based Databases: Small and Beautiful vs. Big and Messy?}

Following Biber et al.'s (1998: 4) definition, a corpus needs to be of a specific size ("large") as well as a "principled" collection of naturally used language. What precisely "large" and "principled" can mean varies greatly when we consider existing corpora of WEs. In the 1960s, a one-million-word corpus was considered "large." Twenty years later, the British National Corpus (BNC) already ran to 100 million words. In the days of "big data," electronic databases of WEs such as the Global Web-Based English (GloWbE) and News on the Web (NOW) corpora comprise 1.9 billion and more than 6 billion words, respectively. The significant increase in corpus size was made possible by technical 
Table 22.1 Comparison of the fiction components in standard written corpora (number of text excerpts per corpus)

\begin{tabular}{lcccc}
\hline \hline Text category & Brown & ACE & WWC & Kolhapur \\
\hline General fiction & 29 & 29 & 29 & 59 \\
Mystery and detective fiction & 24 & 15 & 24 & 24 \\
Science fiction & 6 & 7 & 6 & 2 \\
Western and adventure fiction & 29 & 8 & 29 & 15 \\
Romantic fiction & 29 & 15 & 29 & 18 \\
Humor & 9 & 15 & 9 & 9 \\
Historical fiction & - & 22 & - & - \\
Women's fiction & - & 15 & - & - \\
\hline \hline
\end{tabular}

developments. However, in the WEs context, corpus size can still be restricted by the availability of certain text categories. Literary production in a particular country may be limited, for instance. This can be the case with respect to specific literary genres even in countries where English is the first or "native" language (ENL) of the majority of speakers, such as Australia and New Zealand. Literary production in English typically tends to be limited in contexts where English is only used as an institutionalized second language (ESL) variety competing with other national languages in the area of creative language use, as is the case in India, where more specialized literary genres proved difficult to obtain. Table 22.1 illustrates the point by giving the different numbers of text samples included in the fiction component of the Browntype corpora in Australia (ACE), New Zealand (WWC), and India (Kolhapur).

Availability of texts for a given sampling frame becomes even more problematic in much smaller ESL countries such as Fiji, where not only local text production (e.g. the limited number of local newspapers and magazines) posed a problem for corpus compilation but also the political situation between 2006 and 2015 (i.e. at a period when parliament was resolved, making the sampling of parliamentary debates impossible for a time; see Biewer et al. 2010).

With respect to corpus size, the bigger is not necessarily always the better. For a study of prepositional complements in WEs, for instance, a corpus of one million words already provides too much information for comprehensive and detailed analysis, especially seeing that Prepositional Phrase (PP) attachment is notoriously difficult to model in both qualitative and computational approaches (e.g. Schütze 1995; Volk 2001; Agire et al. 2008). ${ }^{2}$ The counts in Table 22.2 therefore give only a very rough indication of prepositional complements in the various components of ICE.

\footnotetext{
2 PP attachment is difficult, among other things, because of ambiguity: In a sentence like He opened the box with the knife, the PP with the knife could be attached to open (and would therefore be an argument of the main clause) or to the box (as a post-modifier and thus not an argument). Moreover, the distinction between arguments and adjuncts is not clear-cut, either (see Hoffmann 2007 for detailed discussion). Automatic parsing, finally, may identify prepositional complements correctly, as in I'll come and deliver it to you (ICE-GB, S1A-064) or incorrectly, as in I kept it in case he wanted to see it (ICE-GB, S1A-065).
} 
Table 22.2 Automatically retrieved PP complements from syntactically parsed ICE corpora

\begin{tabular}{lllllllll}
\hline \hline ICE component & GB & CAN & IRE & NZ & IND & SG & HK & PHI \\
PP complements & 21,316 & 20,935 & 20,954 & 23,918 & 21,083 & 20,058 & 21,825 & 20,556 \\
\hline \hline
\end{tabular}

Table 22.3 Complementation patterns of enter in ICE (figures in brackets report concrete spatial use of into)

\begin{tabular}{lccccccr}
\hline \hline & absolute & NP/nominal clause & into/onto & in & other P & NP + P & total \\
\hline ICE-GB & 10 & 58 & $11(1)$ & 1 & 1 & 0 & 81 \\
ICE-NZ & 15 & 89 & $13(1)$ & 1 & 1 & 3 & 122 \\
ICE-IND & 11 & 88 & $29(14)$ & 2 & 1 & 1 & 132 \\
ICE-SG & 13 & 47 & $9(1)$ & 1 & 3 & 3 & 76 \\
ICE-HK & 15 & 104 & $18(7)$ & 1 & 3 & 3 & 144 \\
ICE-PHI & 6 & 93 & $20(1)$ & 3 & 1 & 1 & 124 \\
\hline \hline
\end{tabular}

The same corpora can be too small for a related study on lexicogrammatical variation. The verb enter can have a bare Noun Phrase (NP) as complement or a PP, as in He entered (into) the room. The frequencies for these and other complements are rather small in individual ICE components, as Table 22.3 shows. In other words, the size of a corpus required for a particular study always depends on the specific research question(s) and the level of granularity that the analyses aim to provide. The small and carefully compiled corpora may therefore be complemented with large (often web-based) databases (see, e.g., De Clerck and Vanopstal 2015). Where even these fail to provide sufficient evidence they can be combined with other data, for example from experiments. Horch (2019) uses webbased psycholinguistic experimentation (an online maze task) to verify the more widespread use of conversion for deverbal nouns in ESL varieties. Her study shows that corpus and experimental evidence converge, which in turn validates the usefulness of web-based corpora like GloWbE.

The question of what constitutes a "principled" text collection is similarly difficult to answer. In order for statistical modeling to be applied at a later stage, sampling should, in principle, be representative of the "population." For any living language at large, this means that much more spontaneous spoken interaction would have to be included in order to reflect the fact that people use language more often in the spoken than in the written medium. Since spoken corpora have been extremely costly to compile, most corpora are skewed toward the written mode. However, even for printed AmE texts published in a single year, truly representative sampling is impossible to achieve in the theoretical sense. ${ }^{3}$ In practice, corpus compilers therefore

\footnotetext{
${ }^{3}$ Strictly speaking, one would first have to compile a list of all texts printed during that year and then enter this list using a random number table to select individual texts, the page on which to start sampling, etc. (for a more detailed discussion and the pragmatic solution to sampling in linguistic research, see Woods et al. 1986, chap. 4).
} 
apply judgment sampling to arrive at a balanced selection of various spoken and written text categories, where "judgment" "refers to the ability professionally competent members of a speech community seem to have in recognizing the relative prevalence of different genres" (Leech, 2007: 140). ${ }^{4}$ The Brown-type corpora and the components of ICE are based on such judgment samples. However, a sampling frame that provides a good selection of spoken and written material in a largely monolingual ENL country may not necessarily provide a suitable sampling frame for ESL countries where English is used with varying competence and alongside other languages.

Finally, there is a connection between size and sampling principles: Typically, smaller corpora tend to be subjected to stricter sampling criteria and the careful selection of individual text extracts or speakers, including the collection of socio-economic background data for the latter, whereas large mega-corpora often use more coarse-grained sampling frames and a more generous policy on the inclusion of individual samples, on the assumption that a single specimen is unlikely to skew the results from a sufficiently large corpus. ${ }^{5}$ Again, however, the question whether preference should be given to a small and carefully compiled corpus or a "messy" mega corpus cannot be answered without reference to the research question. While for a study on mandative subjunctives across different Englishes, the one-million-word ICE components yield just about enough evidence for a general assessment of usage patterns, more fine-grained analyses with respect to individual trigger expressions such as demand or require necessitate larger amounts of data from less rigorously compiled databases. Web-based corpora such as GloWbE have to be used advisedly, however: In their manual postediting of the data, linguists may want to remove individual instances from their data sets. GloWbE, for instance, contains blogs in order to represent informal language use on the Internet. These occasionally include data from expatriate bloggers, which could have a skewing effect for the study of low-frequency phenomena (see Hundt 2018). ${ }^{6}$ When they are used with the necessary degree of caution, web-based data may usefully complement evidence from smaller corpora.

The GloWbE and NOW corpora are examples of how the World-Wide Web can be used for corpus compilation. Similarly, web-based versions of the original Brown and LOB corpora have been compiled in Lancaster for the study of recent change (see Section 22.5). Researchers have also explored the web-as-corpus approach, either with the help of freely available search engines or on the basis of specifically developed meta-crawlers (see Hundt et al. 2007). Hundt (2013a) uses the progressive passive, as a case

\footnotetext{
${ }^{4}$ For more detailed discussions of representativeness, see, e.g., Biber (1993) or Leech (2007).

5 See Hundt and Leech (2012) and Davies (2012) for a discussion of the "small and beautiful" vs. the "size matters" approach to sampling.

${ }^{6}$ The GloWbE and its potential uses are introduced in more detail in Davies and Fuchs (2015). The advantages and potential pitfalls involved in using this resource are discussed in a number of responses by Christian Mair, Joybrato Mukherjee, Gerald Nelson, and Pam Peters in the same journal.
} 
study to compare the web-as-corpus and web-for-corpus building approach in the context of WEs research. Both approaches are found to provide useful evidence on a low-frequency phenomenon that supplement findings on standard reference corpora. In addition, the web-as-corpus approach returns interesting meta-linguistic comments on the issue of grammaticality, that is, the question whether nonfinite (having been being Ved) or present perfect modal progressive passives (could have been being Ved) are viable constructions of English. The web-as-corpus approach provides evidence of such very rare verb phrases:

(2) The 2017 Australian PrEP Guidelines have the benefits of having been being written and edited by clinicians, epidemiologists and representatives of peak Australian HIV community organisations who have significant experience of PrEP in the clinical, research and realworld settings.

(3) Most physicians believed that the quality targets had improved patient care by focussing attention on necessary clinical activities that might have been being neglected. ${ }^{7}$

In 2007, when new web-based mega-corpora were making an appearance on the scene, Geoffrey Leech - one of the founding fathers of English corpus linguistics - asked whether linguists should use these "[n]ew resources or just better old ones?” Ten years later, Guillaume Desagulier (2017) finds that there is still quite a bit of mileage in the old resources, not least to replicate the results of earlier research with new methodologies such as correspondence analysis. In a blog entry that reports on a replication of Hirschmüller's (1989) study on complex prepositions in IndE, he concludes that "comparatively speaking, the older corpora have the kind of spick-and-span internal structure that makes them pleasant to use."

\subsection{From Metropolitan Varieties to Learner Englishes: The Broadening Scope of Corpus-Based Research}

The study of regional variation in a number of standard WEs was made possible early on through the compilation of Brown-type reference corpora. With the exception of the Kolhapur Corpus, however, they provided evidence for ENL varieties only. The scope of corpus-based research into WEs broadened significantly in 1990 with the inception of ICE (Greenbaum 1988, 1996). This resource provides not only a substantial amount of spoken language (60 percent) but also a wide range of ENL

\footnotetext{
7 The examples were retrieved with a simple google search and come from the following websites: Example (2) https://siren.org.au/post-1294/ (accessed 3 October 2018); Example (3) - www.annfammed.org/content/6/3/228 full.pdf (accessed 3 October 2018).
} 
and ESL varieties as well as samples of English from countries like Jamaica, where standard English is used as a second dialect (ESD) alongside an English-based creole.

The 500 samples of approximately 2,000 words each in the ICE components are spread across four macro text categories: dialogues, monologues, nonprinted, and printed. The largest subsample (a fifth of the material) comes from spontaneous conversations (including telephone conversations). The second largest subsample is drawn from public dialogues (including classroom lessons and broadcast interviews but also more formal interactions such as parliamentary debates). Half of the corpus (250 samples) represent unscripted spoken usage. The sampling frame thus takes into account the fact that the majority of language production happens online and in the spoken medium. It does not, however, aim at a representative sampling of all speakers but intentionally focuses on educated usage. ${ }^{8}$ Moreover, only production in English is part of the corpus, that is, all contributions to a spoken exchange that are in one of the local languages in ESL countries are marked as "extra-corpus" material. ${ }^{9}$

Not all of the eighteen ICE components originally envisaged as part of the project (Greenbaum 1996: 3) were compiled or completed (using material produced between the late 1980s and early 1990s); additional ICE corpora have been compiled (or are being compiled) from more recent material, resulting in a (varying) diachronic bias. ${ }^{10}$ These include varieties such as Malaysian and Malta English, which straddle the divide between ESL and foreign language. While this broadens the regional scope for the corpus-based investigation across WEs, intervarietal research has to take the diachronic dimension into account in the comparison of older with ICE-age II corpora. The diachronic incompatibility of the older and the more recent ICE components is less of a problem with relatively stable regional variation that we would expect to find for instance with the so-called dative alternation than in the investigation of phenomena that underwent rapid change, such as the development of quotative be like.

In addition to the diachronic gap between the early and later ICE corpora, comparability across ICE components is likely to be influenced by stylistic variation that, so far, remains under-researched. Multidimensional (MD) analysis of register variation (see Biber 1985, 1988) is required to gauge the extent to which component parts of ICE are comparable in this respect.

\footnotetext{
${ }^{8}$ Corpora of nonstandard WEs are rarer and often not publicly accessible, as is the case with the corpus of colloquial SingE (Lim, 2004).

9 See Mair (2018: 117) for a critical discussion of the "monolingual" bias of the ICE sampling frame and Lange (2018).

10 The ICE component for Fiji, for instance, was supposed to be part of the original set of ICE corpora but work on the corpus only started in 2005. ICE-US, to the present day, is limited in that only the written component was completed. For a list of available corpora, see www.ice-corpora.uzh.ch/en.html.
} 
In an early attempt at applying the MD approach to ICE components, Xiao (2009) found comparability in some areas (e.g. academic prose and creative writing) and differences in others (e.g. spontaneous spoken conversation). While this study adds useful ideas to expand the original MD approach, it is limited to only one ENL variety (BrE) and four contact varieties of English (Indian, Hong Kong, Singapore, and Philippine English). Kruger and van Rooy (2018) broaden the MD approach considerably by applying it to the written part of sixteen ICE components (both ENL and ESL). While they find that, overall, written registers across ICE components are comparable, they point out that this might not apply to spontaneous conversations: "There may be more extensive differences between varieties in spoken language, especially in face-to-face conversation” (Kruger and van Rooy 2018: 237).

In the last decade, corpus-based research has systematically challenged the traditional divide between ESL and EFL countries. As the contributions to Mukherjee and Hundt (2011) show, usage data frequently do not support the traditional ENL/ESL/EFL divide but provide evidence of some EFL usage coming close to patterns found in ENL varieties (see Section 22.4.1). Moreover, usage patterns considered typical of contact varieties (such as the extended use of the progressive to stative verbs like know) need to be integrated with discussions about conditions on language learning and norm developments. In other words, factors such as the role of second-language learning in the classroom (and beyond) need to be considered as a variable as well as the question whether ESL (but not EFL) varieties are likely to ever start orienting toward an endo-normative model of usage (see Hundt and Mukherjee 2011). The line of research that challenges the ESL/EFL divide has been enabled by the compilation of learner corpora, notably the International Corpus of Learner English (ICLE), which provides a uniform sampling frame for written academic usage. The Louvain International Database of Spoken English Interlanguage (LINDSEI) complements ICLE with spoken data from interviews with advanced learners (see Gilquin 2015). These learner corpora were compiled on the assumption that English as a Foreign Language (EFL) emerges under fundamentally different conditions from those that play a role in the formation of ESL varieties. By contrast, the Corpus of Dutch English takes the sampling frame for the written section of the ICE corpora as its model, that is, focuses on educated written English in a country where the language is not institutionalized but where a large proportion of the population are exposed to English from an early age and use it extensively in their everyday lives (Edwards 2011, 2016, 2017; Edwards and Laporte 2015). Evidence from this corpus even further challenges the divide between ESL and EFL and, together with findings from studies on English in Cyprus or Namibia, has led to recent renegotiations of how WEs should be modeled (see Buschfeld and Kautzsch, Chapter 2, this volume). 


\subsection{From Description to Theoretical and Statistical Modeling}

Corpora can be used for the description of a single variety or varieties in the same region, as is the case in Sand's (1999) study of Jamaican English (JamE) or the papers on SingE collected in Lim (2004). Most of the time, however, descriptions of a single variety use other WEs as a backdrop. Deuber (2014) compares spoken evidence from the Jamaican and Trinidadian ICE components in her study of Caribbean English. The analysis of a range of creole-influenced grammatical features allows her to arrive at a typology of different stylistic connotations. These are then used for a reinterpretation of the creole continuum (pp. 241-243). While Deuber focuses on regional evidence, Zipp (2014) assesses the variety status of educated Fiji English (FE) on the basis of comparisons with BrE, NZE, and IndE. Drawing additionally on evidence from learner corpora allows her to arrive at a fine-grained analysis and interpretation of prepositional usage, also with respect to variety-internal differences between Indo-Fijian and Fijian FE. Intra-varietal comparisons like Deuber (2014) and Zipp (2014) take a local variety or regional usage as their starting point and provide case studies on several features. This approach differs from the focus of most papers in Hundt and Gut (2012): these aim at broad regional coverage for one phenomenon. Finally, individual studies differ in their treatment of variety types: They may juxtapose ENL and ESL varieties (e.g. Collins and Yao, 2012) or use corpus data to test the distinction (e.g. Hundt 2009a).

It is important to note that not only the size and the composition of a corpus determine its usefulness for a specific research question. Developments in the annotation of corpora - notably Part-of-Speech (PoS) tagging and parsing - have also opened up new avenues for research. ${ }^{11}$ Automatic retrieval of passives and corresponding transitive actives, for instance, is only possible once both kinds of meta-information (word class and syntactic function) have been added to the raw text (see Section 22.4.3). Annotation beyond grammatical categories cannot be done automatically and is therefore not universally applied to existing corpus resources. ${ }^{12}$ Ideally, corpus research can also draw on metadata for each sample in the corpus, such as a speaker's age, ethnicity, gender, and so on (cf. Section 22.4.4).

Once a corpus has been enriched by grammatical annotation, it can be fruitfully employed for both top-down and bottom-up approaches to data retrieval. The former takes an existing research hypothesis as its starting point and uses the corpus to verify it. The bottom-up approach uses corpus

\footnotetext{
11 The British ICE component has been annotated with the ICE parser (see Nelson et al. 2002). At Zurich, available ICE corpora have been annotated with a probabilistic dependency parser (Pro3Gres, Schneider 2008). The latter version is searchable to holders of an ICE license through the Dependency Bank jointly developed by Hans Martin Lehmann and Gerold Schneider (see the ICE website).

12 The pragmatically annotated ICE-IRE (Kirk 2016) is an exception.
} 
data in a more explorative fashion. An example would be Schneider and Hundt's (2009) attempt at exploring corpus annotation as a discovery tool for nativization in ESL varieties. The working assumption for this study was that parser output would be erroneous more often in the case of novel patterns typically found in such varieties. However, as it turns out, the parser is too robust for this approach to work. This, in turn, means that automatically annotated data from both ENL and ESL can be taken as a reliable starting point for investigation. Schneider and Hundt (2012) explore an intermediate annotation state between PoS and parsing (called "chunking") to arrive at a bottom-up description of variation in TAM across different WEs.

Corpus-based research into WEs increasingly makes use not only of richer, annotated data but also of various kinds of statistical modeling, thus moving beyond the significance testing characteristic of research from the 1990s.

The studies discussed in the following sections have been selected to reflect these developments in the field.

\subsubsection{Corpora as a Testing Bed for Models of World Englishes}

Corpus evidence has provided a testing ground for the typologies of different WEs (including Kachru's Three Circles Model), Schneider's (2003, 2007) Dynamic Model, and the Epicenter Hypothesis. With respect to Kachru's (1985) Three Circles Model, numerical evidence on individual grammatical patterns does not necessarily support the distinction between ENL, ESL, and EFL varieties: Taking a grassroots perspective, Hundt and Vogel (2011) show that not all ESL varieties share with learner Englishes a propensity to overuse the progressive. Szmrecsanyi and Kortmann's (2011) bird's-eye view does provide evidence of an ESL/EFL divide. They compare evidence from the BNC, ICE, and ICLE on a set of features to characterize grammatical syntheticity and analyticity, respectively. Their study shows that learner varieties systematically differ from ESL varieties when compared with a single ENL (BrE): Learner Englishes are more analytic than ESL varieties, which in turn are more analytic than comparable BrE writing (Szmrecsanyi and Kortmann, 2011: 182).

Synchronic corpora of WEs have also been used to test the validity of Schneider's Dynamic Model of the evolution of WEs, in particular different degrees of nativization. ${ }^{13}$ In doing so, corpus linguists have followed the explicit suggestion by Schneider (2004: 227) that "[t]he most promising road to a possible detection of early traces of distinctive features is a principled comparison of performance data collected along similar lines, i.e. systematically elicited corpora.” Early examples are Mukherjee and Gries (2009) and Gries and Mukherjee (2010). While Mukherjee and

${ }^{13}$ For a diachronic approach, see Section 22.5. 
Gries' (2009) collostruction analysis reveals that a variety's divergence from BrE tallies well with its respective developmental stage, Gries and Mukherjee's (2010) study of lexical bundles did not provide additional evidence that the more advanced a variety is in the evolutionary cycle, the more it will have developed region-specific usage patterns. Gries and Mukherjee (2010: 537) conclude that developmental stages are "less likely to be reflected in lexical differences because lexis-related differences are topic-dependent and volatile."

Corpus data have also been used to test the hypothesis that new Englishes may develop into regional standard varieties and eventually become local norm-providing centers (Bailey 1990: 85). While it is relatively easy to empirically verify that a variety has diverged enough from its original input variety and stabilized to the degree that it can now be considered a new (regional) standard variety of English, it is more difficult to prove exclusively through corpus evidence that this variety is also serving as a new local epicenter (see Hundt 2013b). Existing corpus-based research (e.g. Hoffmann et al. 2011; Biewer 2015) does not normally go beyond testing for relative structural closeness of the varieties in question, that is, it provides indirect evidence of potential epicenter status. Gries and Bernaisch (2016) and Heller et al. (2017) use two well-tried alternations (the dative alternation with GIVE and the genitive alternation) and Multifactorial Prediction and Deviation Analysis with Regression (MuPDAR) to argue that underlying patterns of usage are sufficient to test epicenter status. According to their data, this can be supported for IndE in South Asia but not for SingE in Southeast Asia. These studies still need to be supplemented with evidence on whether language users in countries like Sri Lanka or Bangladesh actually accept IndE as a local norm-providing variety.

\subsubsection{Corpus Evidence, Language Contact, and Typology}

Corpus data have served to model the influence of language contact on different types of Englishes. Szmrecsanyi (2009), for instance, combines the data from various ICE components and compares them with data from the Brown family, the BNC, a corpus of traditional British dialects, and a corpus of spoken AmE. He finds not only that ENL varieties exhibit a significantly higher degree of syntheticity than ESL varieties but also that there is a marked difference between varieties in Southeast Asia (SingE, PhilE, HKE) and non-Southeast Asian varieties (IndE, JamE, East African English; Szmrecsanyi 2009: 328-329). The observation that Southeast Asian varieties use less overt grammatical marking in general aligns well with typological differences of the underlying substrate languages described in Bisang (2009), as Szmrecsanyi (2009: 331) observes.

Brunner (2014) provides a close-up of the role that substrate influence might have for noun phrase complexity in just two WEs with typologically 
different substrates, SingE and Kenyan English (KenE), using BrE as the ENL yardstick. This allows him to consider the specifics of NP structure in various substrate languages in Kenya and Singapore in more detail (i.e. African languages from three different branches of African languages and three varieties of Chinese as well as Malay, respectively). He predicts two potential outcomes for KenE and SingE - a greater frequency of head-initial NPs in KenE (p. 29) and overall simpler NPs in the ESL than in the ENL variety (p. 30) - and tests these hypotheses on random samples of NPs from the spontaneous conversations in the respective ICE components. ${ }^{14}$ Corpus data confirm that KenE has a strong preference for head-initial NPs and disprefers head-final structures, whereas SingE has the opposite preference (p. 37). With respect to NP complexity in ESL and ENL varieties, Brunner's results show that BrE and KenE occupy two endpoints on a cline with SingE in the middle. According to Brunner (2014: 44), the results for hypothesis 1 provide a good argument in favor of substrate language effects, whereas the results for hypothesis 2 tie in with predictions from Schneider's (2003, 2007) Dynamic Model.

\subsubsection{Modeling Morpho-syntactic Variation across World Englishes}

Comparative studies of variable morphology across WEs are relatively rare, mostly because English is a morphologically impoverished language. One of the possible phenomena that has been studied is the (re)regularization of irregular verb morphology. ${ }^{15}$ Table 22.4 provides information on the proportion of irregular $\{-\mathrm{t}\}$ and regular $\{$-ed $\}$ in verbs such as burn, dream, and learn across ENL and ESL varieties in ICE. ${ }^{16}$

While the figures in Table 22.4 obviously abstract away from a more complex situation in that they only give information on overtly marked past tense/participle forms (i.e. ignore the potentially unmarked past forms in, e.g., ICE-SG or ICE-HK), they provide interesting data for the typology that groups WEs according to their matrilect: NZE and AusE are more conservative in this ongoing change than BrE, while IrE is more advanced (pair-wise significance tests with $\mathrm{BrE}$ as a yardstick prove that only the difference between AusE and BrE is significant). Canadian English (CanE), the variety that derives from BrE but is geographically closest to US English, is significantly more advanced in the (re)regularization of regular past tense forms (also than IrE). With respect to ESL varieties, Philippine

\footnotetext{
14 The East African component of ICE comprises both Kenyan and Tanzanian samples. Brunner includes only NPs from Kenyan conversations in his dataset (2014: 30).

15 The change from $\{-t\}$ to $\{$-ed $\}$ is a case of (re)regularization because the irregular forms were only introduced from the Middle English period onwards and then re-regularized in the nineteenth century (see Hundt 2009b and Anderwald 2014 for details).

${ }^{16}$ The totals are based on a search for the variable forms of the verbs burn, dream, kneel, lean, leap, learn, spell, spill and spoil. Figures for ICE-AUS, ICE-NZ and ICE-GB are from Peters (2009: 23). The study by De Clerck and Vanopstal (2015) only uses the written part of the ICE corpora and is limited to ICE-GB, ICE-US and ICE-IND. Adjectival uses of the past participle (as in a learned woman or a burnt piece of toast) are excluded from the counts.
} 
Table 22.4 Relative frequency of - $\mathrm{t}$ and -ed forms across ICE corpora

\begin{tabular}{lrrl}
\hline \hline & $\{$-t $\}$ & $\{$-ed & $\%\{$-ed $\}$ \\
\hline ICE-GB & 55 & 62 & 53 \\
ICE-NZ & 79 & 68 & 46.3 \\
ICE-AUS & 85 & 42 & 33.1 \\
ICE-CAN & 19 & 131 & 87.3 \\
ICE-IRE & 43 & 67 & 60.9 \\
ICE-IND & 116 & 28 & 19.4 \\
ICE-SG & 91 & 33 & 26.6 \\
ICE-HK & 59 & 40 & 40.4 \\
ICE-PHI & 4 & 164 & 97.6 \\
Total & 551 & 635 & 53.5 \\
& & & (average) \\
\hline
\end{tabular}

English (PhilE) is almost categorical in its use of regular forms and thus closest to US English (see, e.g., De Clerck and Vanopstal 2015). IndE and SingE are even more conservative than AusE (IndE significantly so), whereas the proportion of regular forms in ICE-HK is close to those in ICENZ but still significantly different from ICE-GB. The results in Table 22.4 only serve as an initial starting point for a study that would need to rely on larger corpora to dig deeper into the marked differences between lexical items where ICE does not provide sufficient evidence. ${ }^{17}$ Larger amounts of data could then be subjected to the kind of statistical modeling that De Clerck and Vanopstal (2015) apply to the Brown-family corpora, Kolhapur, and supplementary data from GloWbE.

Corpus-based research on syntactic variation greatly benefits from syntactic annotation. Studying the active:passive alternation across WEs has only become feasible with the parsing of the ICE corpora. Hundt et al.'s (2016) study of the parsed academic writing sections in ICE shows that US English is the regional variety which is markedly different from all other Englishes (both ENL and ESL) in avoiding the passive. However, regression analysis reveals that differences across academic subdisciplines are even more marked than regional differences. This demonstrates the need for multifactorial analysis to gauge the relative importance of regional variety as a predictor variable in variationist research into WEs. Similarly, when testing for the role that language-internal factors play in the voice alternation, Hundt et al. (2018) show that there is no general difference across ENL and ESL varieties. However, differences in the effect size that some factors have provide evidence of subtle regional variation across academic Englishes, some of which find an explanation in substrate influence even in a highly edited register such as academic writing. In the Philippine ICE

17 The most frequent alternating verb is LEARN. The regular form of this verb may function as an adjective, a use that is particularly frequent in ICE-IND, ICE-SG and ICE-HK. 
data, for instance, GIVENNESS of the subject has a stronger effect on the choice of a passive, which fits in well with the requirement of the main substrate language, Tagalog, where sentences are required to have at least one given argument (Hundt et al. 2018: 9, 26).

The application of sophisticated statistical modeling to WEs is a relatively recent phenomenon. A good example is Szmrecsanyi et al.'s (2016) study of the dative, genitive, and particle placement alternations. They use two multivariate models, a conditional inference tree and a random forest analysis. ${ }^{18}$ Their aim is to investigate whether the three alternations provide evidence of "probabilistic indigenization" (2016: 133), which they define as

the process whereby stochastic patterns of internal linguistic variation are reshaped by shifting usage frequencies in speakers of post-colonial varieties. To the extent that patterns of variation in a new variety A, e.g. the probability of item $\mathrm{x}$ in context $\mathrm{y}$, can be shown to differ from those of the mother variety, we can say that the new pattern represents a novel, if gradient, development in the grammar of A. These patterns need not be consistent or stable ..., but they nonetheless reflect the emergence of a unique, region-specific grammar.

Szmrecsanyi et al. (2016: 133) find that regional variety is the most important predictor for the particle placement alternation, whereas the genitive alternation is the least subject to regional variation. They suggest that regional variety is the more likely to have an effect on speakers' choices the more individual lexical items play a role in the alternation.

\subsubsection{Corpus-Based Modeling of Sociolinguistic and Pragmatic Variation across World Englishes}

Systematic use of publicly available corpora for sociolinguistic research into WEs is still rare, partly because the metadata for the ICE corpora that provide information on speaker background are not readily available. ${ }^{19}$ Mair (2009) is as an early proponent of this approach. Having been involved in the compilation of ICE-JAM himself, he compares educated JamE with BrE, IndE, SingE, HKE, and PhilE. However, in his case studies on lexical, syntactic, and pragmatic features, he does not include speaker variables. Zipp (2014) systematically takes ethnicity into account in her study of educated Fiji English but, like Mair (2009), does not include

\footnotetext{
18 This statistical approach was developed by psychologists and later applied to the modeling of linguistic data. The most comprehensive comparison of more traditional multivariate analyses and the tree-and-forest approach can be found in Tagliamonte and Baayen (2012).

${ }^{19}$ For an overview of ICE corpora with metadata on individual speakers, see Lang (2018: 23). Sharma (2017) provides a thorough discussion of the theoretical underpinnings for the sociolinguistics of WEs. A workshop at the 38th ICAME conference in Prague (2017) on genderlectal variation across ESL and EFL varieties is indicative of a growing interest in sociolinguistic exploration of WEs corpora. Some researchers (e.g. Sigley and Holmes 2002) have used corpora to investigate sexist language use across WES, which also falls under the heading of sociolinguistic corpus-based research.
} 
information on the speaker level in her investigation. Gut and Fuchs (2014) set out to study speaker fluency across two phonologically annotated ICE corpora. Despite the title of their paper, they only compare speaker fluency (in terms of mean length of utterance) in Nigerian and Scottish English without reference to the individual speaker. ${ }^{20}$

Höhn (2012) uses multivariate analysis on the spoken components of ICE-JAM and ICE-IRE for a socio-pragmatic study on the developmental trajectory of quotative be like, dividing the data into two collection periods (1990-1994 and 2002-2005). With respect to the speaker variable "gender," she finds that "the corpus is too skewed in favour of women in the period 2002 to 2005 to allow a firm statement" (2012: 288). Höhn's study thus nicely illustrates the problem inherent in the ICE corpora for the study of socio-pragmatic variation: The corpora were primarily designed to study variation across WEs. This means that speaker variables such as age, gender, ethnicity, first language, and so on were not necessarily controlled for in the sampling of the data.

Studies of socio-phonetic variation based on ICE corpora are even rarer than sociolinguistic studies generally, mostly because the recordings themselves are not available to the academic community at large. Rosenfelder's (2009) study on rhoticity in educated JamE is therefore particularly unusual as she combines variation at the speaker level with a socio-phonetic variable. She finds that contextual variables are significant in predicting rhoticity; somewhat surprisingly, "gender" and "age" as speaker variables are not significant (Rosenfelder, 2009: 73).

Vine (2000) is an early publication that critically discusses the methodological challenges involved in using ICE data for the study of pragmatic phenomena. One of the main problems in her comparative study of directives in ICE-GB and ICE-NZ turned out to be corpus comparability:

[T]he same section in each component contained different types of interactions. ICE-NZ's demonstrations include cooking and Tupperware demonstrations, while ICE-GB's are mostly academic ... These different types of demonstrations yield very different types of directives.

(Vine, 2000: 379)

Despite these challenges, ICE corpora have regularly been used to study aspects of pragmatics across WEs, such as discourse particles (Lange 2009) or invariant isn't it (Parviainen 2016). ICE corpora are also used to study pragmatic variation in individual varieties, as in Wong (2010), Heine et al. (2017), and Unuabonah and Gut (2018). These studies can serve as starting points for cross-varietal comparisons.

\footnotetext{
${ }^{20}$ Note, however, that the purpose of their case study is primarily to demonstrate the added value that phonologically annotated corpora provide.
} 


\subsection{Synchronic, "Brachryonic," and Diachronic Evidence: Corpus-Based Investigation of Change in World Englishes}

Since genuine diachronic data are missing for most ESL varieties of English, ${ }^{21}$ Fuchs and Gut (2015) use the apparent-time approach and regression analysis on their ICE-Nigeria data to study the spread of the progressive in this variety: "The results show that younger speakers use more progressives than older speakers, which we interpret as evidence for ongoing language change" (Fuchs and Gut, 2015: 373). Interestingly, the spread cannot be attributed to an increase in extended uses of the progressive to stative verbs (as in Example (4)), so often associated with ESL and EFL varieties (ibid.).

(4) we are believing that erm in three years' time there will be a railway. (ICE-NIG, S1B-32)

Similarly, Hansen (2017: 479-481) is able to use apparent-time data to demonstrate how must gives way to have to in HKE, with female speakers leading the change (p. 482).

The apparent-time concept is applied in a much looser fashion in Mair and Winkle's (2012) study of the shift from to-infinitive to bare infinitive in specificational cleft sentences (e.g. What she did was (to) call him on her mobile). Having established that there is a real-time change in two reference varieties (BrE and US English), they use synchronic evidence from different ICE components and interpret differences between varieties as indicative of regional differences in this ongoing change:

It is highly likely that these varieties also share in the drift toward the bare infinitive, so that a higher frequency of this form in comparison to ICE-GB should be interpreted as a sign of faster diachronic change, while a lower frequency would be a sign of a relatively more retarded stage in the development.

(Mair and Winkle, 2012: 247)

In a similar vein, van der Auwera et al. (2012) establish recent real-time change in the use of need (to) in BrE and AmE as their baseline before moving on to interpret synchronic ICE data as evidence of convergence and divergence of ESL varieties from the reference varieties. In particular, they argue that change is more advanced in speech than in writing, that is, they take stylistic variation in present-day English as a proxy for ongoing change. They are cautious in interpreting their results as hard evidence of diachronic developments, though, not only because they use synchronic data as a proxy for change but also because of low token frequencies (van der Auwera et al. 2012: 72).

21 The focus in this section is on morpho-syntactic change in WEs. For available evidence on accent evolution, see Huber, Chapter 21, this volume. This section also refers to diachronic corpora that are not (yet) in the public domain. 
Both Mair and Winkle (2012) and van der Auwera et al. (2012) use realtime evidence from the Brown-family corpora ${ }^{22}$ to establish their diachronic benchmark, that is, the earlier and later replica corpora sampled from material published thirty years prior and after the publication of the original Brown and LOB evidence. Mair (1994: 130-131) adopts Lehmann's (1991) term "brachychronic" (literally "short-time”) both for recent change and for the corpus-based description of it. Initially, Brownfamily corpora were used to study brachychronic change in BrE and AmE (Leech et al., 2009). ${ }^{23}$

More recently, the brachychronic approach has been extended beyond ENL varieties. Collins et al. (2014) use evidence from a Brown-type corpus of PhilE from the 1950s/1960s and comparative data from ICE to study change in core and quasi-modals. According to this evidence, PhilE is seen as realigning itself with its matrilect, AmE. Gries et al. (2018) use brachychronic evidence on the genitive alternation from a Brown-type corpus of SingE and ICE-SG and comparative data from ICE-GB. Applying the MuPDAR approach (see Section 22.4.1), their aim is to verify Schneider's (2007: 155) claim that SingE transitioned from stage 3 (nativization) into stage 4 (endonormative stabilization) in the 1970s. Their results do not provide unambiguous proof of structural divergence (2018: 273), if structural divergence is what the model indeed predicts in this case. They go on to discuss the issues involved in operationalizing Schneider's model for corpus-linguistic research (2018: 273-276) and conclude that additional corpus-based research based on real-time evidence is needed for each of the WEs to test the hypotheses against a number of linguistic variables. Similar corpora for the study of recent change in ESL varieties are being compiled for HKE (Biewer et al. 2014) and Ghanaian English (Brato 2018).

Real-time diachronic change into varieties of English was first enabled by the compilation of ARCHER, A Representative Corpus of Historical English Registers. ${ }^{24}$ The purpose behind the compilation of the corpus was to study diachronic shifts in registers but it can also be used to study differential change in BrE and AmE (for an ARCHER-based typology of change that goes beyond the "lag" vs. "innovation" dichotomy, see Hundt 2009b).

Corpora for other ENL varieties followed suit, such as the Corpus of $\mathrm{Oz}$ Early English (COOEE; Fritz 2007) and the Corpus of Early New Zealand English

\footnotetext{
22 The original Brown family extended the time frame from 1961 to 1991/1992 (FLOB and Frown); the extended Brown family adds corpora from the 1930 s (B-LOB and B-Brown). The web-based extensions into the twenty-first century are the AEO6 and BEO6 corpora compiled at Lancaster (see Hundt and Leech 2012).

${ }^{23}$ In his recent study that includes changes in spelling, word formation, and semantics, Baker (2017) draws on the extended Brown family (see Hundt and Leech 2012) and supplements these corpora with real-time evidence from the original BNC and its 2014 update. The brachychronic approach can also be pursued with the Strathy Corpus of CanE, which was originally sampled on the basis of the Brown sampling frame and since expanded to include more recent material as well as spoken data.

${ }^{24}$ Incidentally, the corpus was introduced at the same time that Mair (1994) adopted the term "brachychronic" for recent and ongoing change (see Biber et al. 1994).
} 
(Hundt 2012). ${ }^{25}$ Collins (2015) compares COOEE with evidence from ARCHER for a number of morpho-syntactic features, which enables him to chart how AusE has shifted away from its matrilect and toward AmE, the center of gravity for various (recent) changes in English. Hundt and Szmrecsanyi (2012) and Hundt (2015) provide case studies on the progressive, the genitive alternation, and do-support in early NZE and AusE vis-àvis $\mathrm{BrE}$ and $\mathrm{AmE}$. Their results show that the direction of change is not necessarily one away from BrE to an American model but that some changes can occur in tandem.

As with synchronic corpora of WEs, the Web has also been used to collect mega-diachronic corpora of AmE and BrE (the Corpus of Historical American English, COHA, and the Corpus of Late Modern English Texts, CLMET, respectively), but there are no matching corpora of other WEs to enable cross-varietal diachronic research yet. In addition to the stratified corpora, a number of single-genre corpora exist, such as the Corpus of Irish English Correspondence (CORIECOR).

One of the challenges for the compilation of historical corpora of WEs, especially for the early stages, is the question when an emigrant should count as a speaker of the new variety (see Hundt 2012 for a more detailed discussion). For ESL varieties, a more serious problem is the availability (or accessibility) of material from the colonial period. It is therefore not surprising that the compilation of genuine diachronic corpora for ESL varieties has been seen as one of the central requirements for corpus-based research into WEs (e.g. Mukherjee and Schilk, 2012: 190; Hundt, 2016a: 345; Mair, 2018: 118). While there are no resources comparable to ARCHER, for instance, for ESL varieties, progress can still be made on the basis of other materials. On the basis of Legislative Council proceedings, Evans (2015) charts the development of regional lexis to demonstrate that Hong Kong English (HKE) shows the effect of nativization later than predicted in previous research: "If indeed English is being nativized in Hong Kong, this process is likely to have commenced at least two decades later than Schneider (2007) claims. This points to the need for an alternative periodization" (Evans 2015: 189). However, he also concedes that investigating lexical nativization is only one piece in the jigsaw puzzle: "Thus, if we wish [to, $\mathrm{MH}$ ] test the model, we need to examine the framework as a whole, not just one element (lexis) of one of the four parameters (linguistic effects)" (Evans 2015: 192).

\subsection{Outlook}

The inception of ICE was an important milestone for the corpus-based investigation of WEs. The corpora have resulted in a rich body of existing

\footnotetext{
25 The Corpus of Early Ontario English (Dollinger 2005) uses a similar sampling frame as ARCHER but is regionally restricted rather than providing a sample of early CanE as a whole.
} 
research, of which only a tiny fraction could be reviewed in this chapter. While ICE is an immensely useful resource, its full potential has not been exploited yet, especially with respect to sociolinguistic variationist approaches. Making existing metadata available in a user-friendly interface is one of the developments that will hopefully further advance corpusbased research into WEs in the near future. One of the original deliverables of the ICE project - alignment of the original recordings with the transcripts (Kirk 2017: 373) - has not been achieved (with a few exceptions). It would provide an important additional avenue, especially for systematic cross-varietal socio-phonetic studies. In combination with statistical approaches that can deal with small and skewed data sets, researchers would be able to arrive at more fine-grained intra- and intervarietal descriptions of variation.

Despite the technical advances, mega-corpora of natural conversations from a broad range of WEs and a representative sample of speakers are still not available. With recent developments in machine learning and speech recognition, the digitization of spontaneous spoken language has become much less costly. This will hopefully advance corpus building in the near future. However, bigger corpora of spoken language will only provide useful if they are sampled carefully and fully documented, particularly with respect to speaker variables.

It is advisable to supplement evidence from synchronic corpora with historical data since patterns that are identified as instances of nativization in ESL varieties (e.g. the extension of pluralization to non-counts) may also have precursors in earlier stages of English (Hundt 2016b, Schneider et al., 2019). In other words, for the historical study of WEs, researchers not only need stratified diachronic corpora of ESL varieties to fill in the gaps but ideally also diachronic evidence on regional and nonstandard varieties of English to gauge the effect that different input varieties may have had on the development of WEs. At the end of the day, however, any corpus-based investigation of WEs needs to start from theory-informed hypotheses and should, ideally, feed back into advancing theories of WEs.

\section{References}

\section{Corpora}

ACE = Australian Corpus of English (Written Australian English, 1986)

AmE06 = Web-derived 2006 Brown Corpus (Written American English, 2006)

ARCHER = A Representative Corpus of Historical English Registers [www .helsinki.fi/varieng/CoRD/corpora/ARCHER/updated\%20ver sion/background.html\#history]

B-Brown = Before Brown Corpus (Written American English, 1930s) 


\begin{tabular}{|c|c|}
\hline & = Web-derived 2006 LOB Corpus (Written British English, 2006) \\
\hline & = Before LOB Corpus (Written British English, 1930s) \\
\hline NC & $\begin{aligned}= & \text { British National Corpus (Spoken and Written British English, } \\
& \text { 1991-1994; 2014) [www.natcorp.ox.ac.uk] }\end{aligned}$ \\
\hline own & = Brown Corpus (Written American English, 1961) \\
\hline ENZE & = Corpus of Early New Zealand English (see Hundt 2012) \\
\hline LMET & $\begin{aligned}= & \text { Corpus of Late Modern English Texts [www.helsinki.fi/varieng/ } \\
& \text { CoRD/corpora/CLMETEV/index.html] }\end{aligned}$ \\
\hline OHA & $\begin{aligned}= & \text { Corpus of Historical American English [https://corpus.byu.edu } \\
& \text { /coha/] }\end{aligned}$ \\
\hline ONTE & = Corpus of Early Ontario English (see Dollinger 2005) \\
\hline OOEE & = Corpus of Oz Early English (see Fritz 2007) \\
\hline ORIECOR & $\begin{aligned}= & \text { Corpus of Irish English Correspondence (see McCafferty \& } \\
& \text { Amador-Moreno 2012) }\end{aligned}$ \\
\hline own & = Freiburg Brown Corpus (Written American English, 1992) \\
\hline $\mathrm{OB}$ & = Freiburg LOB Corpus (Written British English, 1991) \\
\hline loWbE & $\begin{aligned}= & \text { Corpus of Global Web-based English (web-based corpus of } \\
& \text { World Englishes, approximately } 1.9 \text { million words) } \\
& \text { [www.english-corpora.org/glowbe/] }\end{aligned}$ \\
\hline $\mathrm{E}$ & = International Corpus of English [www.ice-corpora.uzh.ch] \\
\hline CLE & $\begin{aligned}= & \text { International Corpus of Learner English (Corpus of argumentative } \\
& \text { essays from university learners of English as a foreign lan- } \\
& \text { guage, with various first language backgrounds) [https:// } \\
& \text { uclouvain.be/en/research-institutes/ilc/cecl/icle.html] }\end{aligned}$ \\
\hline olhapur & $\begin{array}{l}=\text { The Kolhapur Corpus of Indian English (Written Indian English, } \\
\text { 1978) }\end{array}$ \\
\hline INDSEI & $\begin{aligned}= & \text { Louvain International Database of Spoken English Interlanguage } \\
& \text { (Spoken learner interview data, various first languages) [https:// } \\
& \text { uclouvain.be/en/research-institutes/ilc/cecl/lindsei.html] }\end{aligned}$ \\
\hline & = London-Oslo-Bergen Corpus (Written British English, 1961) \\
\hline & $\begin{aligned}= & \text { News on the Web (web-based monitor corpus of } \\
& \text { newspaper archives from twenty countries; since 2010) } \\
& \text { [www.english-corpora.org/now/] }\end{aligned}$ \\
\hline Strathy & $\begin{aligned}= & \text { Strathy Corpus of Canadian English (spoken and written Canadian } \\
& \text { English, } 50 \text { million words; data from the early 1980s until } \\
& \text { 2010; available at BYU) [www.queensu.ca/strathy/corpus] }\end{aligned}$ \\
\hline & $\begin{aligned}= & \text { Wellington Corpus of Written New Zealand English (Written New } \\
& \text { Zealand English, 1986) }\end{aligned}$ \\
\hline
\end{tabular}

\section{Secondary Sources}

Agire, Eneko, Timothy Baldwin and David Martinez. 2008. Improving parsing and PP attachment performance with sense information. Proceedings of ACL-08: 317-325. www.aclweb.org/anthology/P08-1037 
Anderwald, Lieselotte. 2014. Burned, dwelled, dreamed: The evolution of a morphological Americanism, and the role of prescriptive grammar writing. American Speech 89: 408-440.

Bailey, Richard W. 1990. English at its twilight. In Christopher Ricks and Leonard Michaels, eds. The State of the Language. London: Faber and Faber, 83-94.

Baker, Paul. 2017. American and British English: Divided by a Common Language? Cambridge: Cambridge University Press.

Bao, Zhiming. 2010. A usage-based approach to substratum transfer: The case of four unproductive features in Singapore English. Language 86(4): 792-820.

Bao, Zhiming and Lionel Wee. 1999. The passive in Singapore English. World Englishes 18(1): 1-11.

Biber, Douglas. 1985. Investigating macroscopic textual variation through multifeature/multidimensional analyses. Linguistics 23(2): 337-360.

Biber, Douglas. 1988. Variation across Speech and Writing. Cambridge: Cambridge University Press.

Biber, Douglas. 1993. Representativeness in corpus design. Literary and Linguistic Computing 8(4): 243-257.

Biber, Douglas, Susand Conrad and Randi Reppen. 1998. Corpus Linguistics. Investigating Language Structure and Use. Cambridge: Cambridge University Press.

Biber, Douglas, Finegan, Edward, and Atkinson, David. 1994. ARCHER and its challenges: Compiling and exploring A Representative Corpus of Historical English Registers. In Udo Fries, Gunnel Tottie and Peter Schneider, eds., Creating and Using English Language Corpora. Amsterdam: Rodopi, 1-14.

Biewer, Carolin. 2015. South Pacific Englishes. A Sociolinguistic and Morphosyntactic Profile of Fiji English, Samoan English and Cook Islands English. Amsterdam: Benjamins.

Biewer, Carolin, Marianne Hundt and Lena Zipp. 2010. "How" a Fiji corpus? Challenges in the compilation of an ESL ICE component. ICAME Journal, 34:5-23.

Biewer, Carolin, Tobias Bernaisch, Mike Berger and Benedikt Heller. 2014. Compiling the diachronic corpus of Hong Kong English: Motivation, progress and challenges. Poster presented at ICAME 35, Nottingham.

Bisang, Walter. 2009. On the evolution of complexity. Sometimes less is more in East and mainland Southeast Asia. In Geoffrey Sampson David Gil and Peter Trudgill, eds., Language Complexity as an Evolving Variable. Oxford: Oxford University Press, 34-49.

Brato, Thorsten. 2018. "Outdooring” the historical corpus of English in Ghana. English Today 34(2): 25-34.

Brunner, Thomas. 2014. Structural nativization, typology and complexity: Noun phrase structures in British, Kenyan and Singaporean English. English Language and Linguistics 18(1): 23-48. 
Collins, Peter. 2015. Diachronic variation in the grammar of Australian English. Corpus-based explorations. In Peter Collins, ed. Grammatical Change in English World-Wide. Amsterdam: John Benjamins, 15-42.

Collins, Peter, Ariane Borlongan and Xinyue Yao. 2014. Modality in Philippine English: A diachronic study. Journal of English Linguistics 42(1): 68-88.

Collins, Peter and Xinyue Yao. 2012. Modals and quasi-modals in New Englishes. In Marianne Hundt and Ulrike Gut, eds. Mapping Unity and Diversity World-Wide. Corpus-Based Studies of New Englishes. Amsterdam: John Benjamins, 35-54.

Davies, Mark. 2012. Some methodological issues related to corpus-based investigations of recent syntactic changes in English. In Terttu Nevalainen and Elizabeth Closs Traugott, eds. The Oxford Handbook of the History of English. Oxford: Oxford University Press, 157-174.

Davies, Mark, and Robert Fuchs. 2015. Expanding horizons in the study of world Englishes with the 1.9 billion word Global Web-based English Corpus (GloWbE). English World-Wide 36: 1-28.

De Clerck, Bernard and Klaar Vanopstal. 2015. Patterns of regularisation in British, American and Indian English. A closer look at irregular verbs with t/ed variation. In Peter Collins, ed. Grammatical Change in English World-Wide. Amsterdam: Benjamins, 335-371.

Desagulier, Guillaume. 2017. The Indian exception: Complex prepositions in the Kolhapur Corpus. Around the word, December 20. https://corpling .hypotheses.org/284

Deuber, Dagmar. 2014. English in the Caribbean: Variation, Style and Standards in Jamaica and Trinidad. New York: Cambridge University Press.

Dollinger, Stefan 2005. Oh Canada! Towards the Corpus of Early Ontario English. In Antoinette Renouf and Andrew Kehoe, eds. The Changing Face of Corpus Linguistics. Amsterdam: Rodopi, 7-25.

Edwards, Alison. 2011. Introducing the corpus of Dutch English. English Today 27(3): 10-14.

Edwards, Alison. 2016. English in the Netherlands: Functions, Forms and Attitudes. Amsterdam: John Benjamins.

Edwards, Alison. 2017. ICE Age 3: The expanding circle. World Englishes 36(3): 404-426.

Edwards, Alison and Samantha Laporte. 2015. Outer and Expanding Circle Englishes: The competing roles of norm orientation and proficiency levels. English World-Wide 36(2): 135-169.

Evans, Stephen. 2015. Testing the Dynamic Model: The evolution of the Hong Kong English lexicon (1858-2012). Journal of English Linguistics 43(3): 175-200.

Fritz, Clemens W. A. 2007. From English in Australia to Australian English 1788-1900. Frankfurt: Peter Lang. 
Fuchs, Robert and Ulrike Gut. 2015. An apparent time study of the progressive in Nigerian English. In Peter Collins, ed. Grammatical Change in English World-Wide. Amsterdam: John Benjamins, 373-387.

Gilquin, Gaëtanelle. 2015. At the interface of contact linguistics and second language acquisition research. New Englishes and Learner Englishes compared. English World-Wide 36(1): 91-124.

Greenbaum, Sidney. 1988. A proposal for an international computerized corpus of English. World Englishes 7(3): 315.

Greenbaum, Sidney, ed. 1996. Comparing English Worldwide: The International Corpus of English. Oxford: Clarendon Press.

Gries, Stefan and Joybrato Mukherjee. 2010. Lexical gravity across varieties of English: An ICE-based study of n-grams in Asian Englishes. International Journal of Corpus Linguistics 15: 520-548.

Gries, Stefan Th. and Tobias Bernaisch. 2016. Exploring epicentres empirically. Focus on South Asian Englishes. English World-Wide 37(1): 1-25.

Gries, Stefan Th., Tobias Bernaisch and Benedikt Heller. 2018. A corpuslinguistic account of the history of the genitive alternation in Singapore English. In Sandra C. Deshors, ed. Modelling World Englishes. Assessing the Interplay of Emancipation and Globalization of ESL Varieties. Amsterdam: Benjamins, 245-279.

Gut, Ulrike and Robert Fuchs. 2014. Exploring speaker fluency with phonologically annotated ICE corpora. World Englishes 36(3): 387-403.

Hansen, Beke. 2017. The ICE metadata and the study of Hong Kong English. World Englishes 36(3): 471-486.

Heine, Bernd, Gunther Kaltenböck, Tania Kuteva and Haiping Long. 2017. Cooptation as a discourse strategy. Linguistics 55(5): 813-855.

Heller, Benedikt, Tobias Bernaisch and Stefan Th. Gries. 2017. Empirical perspective on two potential epicentres: the genitive alternation in Asian Englishes. ICAME Journal 41: 111-144.

Hirschmüller, Helmut. 1989. The use of complex prepositions in Indian English in comparison with British and American English. In Gottfried Graustein and Wolfgang Thiele, eds. Englische Textlinguistik und Varietätenforschung. [Linguistische Arbeitsberichte 69]. Leipzig: KarlMarx-Universität Leipzig, 52-58.

Hoffmann, Thomas. 2007. Complements versus adjuncts? A construction grammar account of English prepositional phrases. Occasional Papers in Language and Linguistics (University of Nairobi) 3, 92-119.

Hoffmann, Sebastian, Marianne Hundt and Joybrato Mukherjee. 2011. Indian English - an emerging epicentre? A pilot study on light-verbs in web-derived corpora of South Asian Englishes. Anglia 12(3-4): 258-280.

Höhn, Nicole. 2012. “And they were all like 'What's going on?”: New quotatives in Jamaican and Irish English. In Marianne Hundt and Ulrike Gut, eds. Mapping Unity and Diversity World-Wide. Corpus-Based Studies of New Englishes. Amsterdam: John Benjamins, 263-289. 
Horch, Stephanie. 2019. Complementing corpus analysis with web-based experimentation in research on World Englishes. English World-Wide 40(1): 24-52.

Hundt, Marianne. 2009a. Global feature - local norms? A case study on the progressive passive. In Thomas Hoffmann and Lucia Siebers, eds. World Englishes: Problems, Properties and Prospects. Amsterdam: John Benjamins, 287-308.

Hundt, Marianne. 2009b. Colonial lag, colonial innovation, or simply language change? In Günter Rohdenburg and Julia Schlüter, eds. One Language, Two Grammars: Morphosyntactic Differences between British and American English. Cambridge: Cambridge University Press, 13-37.

Hundt, Marianne. 2012. Towards a corpus of early written New Zealand English: News from Erewhon? Te Reo: Journal of the Linguistic Society of New Zealand 55: 51-74.

Hundt, Marianne. 2013a. Using web-based data for the study of global English. In Manfred Krug and Julia Schlüter, eds. Research Methods in Language Variation and Change. Cambridge: Cambridge University Press, 158-177.

Hundt, Marianne. 2013b. The diversification of English: Old, new and emerging epicentres. In Daniel Schreier and Marianne Hundt, eds. English as a Contact Language. Cambridge: Cambridge University Press, 182-203.

Hundt, Marianne. 2015. Do-support in early New Zealand and Australian English. In Peter Collins, ed. Grammatical Change in English World-Wide. Amsterdam: Benjamins, 65-86.

Hundt, Marianne. 2016a. Global spread of English: Processes of change. In Merja Kytö and Päivi Pahta, eds. The Cambridge Handbook of English Historical Linguistics. Cambridge: Cambridge University Press, 335-347.

Hundt, Marianne. 2016b. Error, feature, (incipient) change - or something else altogether? On the role of low-frequency deviant patterns for the description of Englishes. In Elena Seoane and Cristina Suárez-Gómez, eds. World Englishes: New Theoretical and Methodological Considerations. Amsterdam: John Benjamins, 37-60.

Hundt, Marianne. 2018. It is important that mandatives (should) be studied across different World Englishes and from a construction grammar perspective. In Paloma Núñez Pertejo, María José López Couso, Belén Méndez Naya and Ignacio Palacios Martínez, eds. Crossing Linguistic Boundaries: Systemic, Synchronic and Diachronic Variation in English. London: Bloomsbury, 211-238.

Hundt, Marianne, Carolin Biewer and Nadja Nesselhauf, eds. 2007. Corpus Linguistics and the Web. Amsterdam: Rodopi.

Hundt, Marianne and Ulrike Gut, eds. 2012. Mapping Unity and Diversity World-Wide. Corpus-Based Studies of New Englishes. Amsterdam: John Benjamins. 
Hundt, Marianne and Geoffrey Leech. 2012. Small is beautiful - On the value of standard reference corpora for observing recent grammatical change. In Terttu Nevalainen and Elizabeth Closs Traugott, eds. The Oxford Handbook of the History of English. Oxford: Oxford University Press, 175-188.

Hundt, Marianne and Joybrato Mukherjee. 2011. Discussion forum: New Englishes and Learner Englishes - quo vadis? In Joybrato Mukherjee and Marianne Hundt, eds. 2011. Exploring Second-Language Varieties of English and Learner Englishes: Bridging a Paradigm Gap. Amsterdam: John Benjamins, 209-217.

Hundt, Marianne, Melanie Röthlisberger and Elena Seoane. 2018. Predicting voice alternation across academic Englishes. Corpus Linguistics and Linguistic Theory. doi:10.1515/cllt-2017-0050

Hundt, Marianne, Gerold Schneider and Elena Seoane. 2016. The use of the be-passive in academic Englishes: Local vs. global usage in an international language. Corpora 11(1): 31-63.

Hundt, Marianne and Benedikt Szmrecsanyi. 2012. Animacy in early New Zealand English. English World-Wide 33(3): 241-263.

Hundt, Marianne and Katrin Vogel. 2011. Overuse of the progressive in ESL and learner Englishes - Fact or fiction? In Joybrato Mukherjee and Marianne Hundt, eds. Exploring Second-Language Varieties of English and Learner Englishes: Bridging a Paradigm Gap. Amsterdam: John Benjamins, 145-166.

Kachru, Braj B. 1985. Standards, codification and sociolinguistic realism: The English language in the outer circle. In Randolph Quirk and H. G. Widdowson, eds. English in the World: Teaching and Learning the Language and Literatures. Cambridge: Cambridge University Press, 11-30.

Kirk, John. 2016. The pragmatic annotation scheme of the SPICE-Ireland corpus. International Journal of Corpus Linguistics 21(3): 299-323.

Kirk, John. 2017. Developments in the spoken components of ICE corpora. World Englishes 36(3): 371-386.

Kruger, Haidee and Bertus van Rooy. 2018. Register variation in written contact varieties of English. A multidimensional analysis. English WorldWide 39(2): 214-242.

Lange, Claudia. 2009. "Where's the party yaar!” Discourse particles in Indian English. In Thomas Hoffmann and Lucia Siebers, eds. World Englishes: Problems, Properties and Prospects. Amsterdam: Benjamins, 207-225.

Lange, Claudia. 2018. Indian English or Indian Englishes? Accounting for speakers' multilingual repertoires in corpora of postcolonial Englishes. In Arja Nurmi, Tanja Rütten and Päivi Pahta, eds. Challenging the Myth of Monolingual Corpora. Amsterdam: Brill, 16-38.

Leech, Geoffrey. 2007. New resources or just better old ones? The Holy Grail of representativeness. In Marianne Hundt, Nadja Nesselhauf and Carolin Biewer, eds. Corpus Linguistics and the Web. Amsterdam: Rodopi, 133-149. 
Leech, Geoffrey, Marianne Hundt, Christian Mair and Nicholas Smith. 2009. Change in Contemporary English. A Grammatical Study. Cambridge: Cambridge University Press.

Lehmann, Christian. 1991. Grammaticalization and related changes in contemporary German. In Elizabeth Traugott and Bernd Heine, eds. Approaches to Grammaticalization, Vol. 2, Amsterdam: John Benjamins, 493-535.

Lim, Lisa, ed. 2004. Singapore English: A Grammatical Description. Amsterdam: John Benjamins.

McCafferty, Kevin and Amador-Moreno, Carolina P. 2012. A Corpus of Irish English Correspondence (CORIECOR): A tool for studying the history and evolution of Irish English. In Bettina Migge and Máire Ní Chiosáin, eds. New Perspectives on Irish English. Amsterdam: John Benjamins, 265-88.

Mair, Christian. 1994. Is see becoming a conjunction? The study of grammaticalisation as a meeting ground for corpus linguistics and grammatical theory. In Udo Fries, Gunnel Tottie and Peter Schneider, eds. Creating and Using English Language Corpora. Amsterdam: Rodopi, 127-137.

Mair, Christian. 2009. Corpus linguistics meets sociolinguistics: Studying educated spoken usage in Jamaica on the basis of the International Corpus of English. In Thomas Hoffmann and Lucia Siebers, eds. World Englishes: Problems, Properties and Prospects. Amsterdam: John Benjamins, 39-60.

Mair, Christian. 2018. World Englishes and corpora. In Markku Filppula, Juhani Klemola and Devyani Sharma, eds. The Oxford Handbook of World Englishes. Oxford: Oxford University Press, 103-122.

Mair, Christian and Claudia Winkle. 2012. Change from to-infinitive to bare infinitive in specificational cleft sentences: Data from World Englishes. In Marianne Hundt and Ulrike Gut, eds. Mapping Unity and Diversity World-Wide: Corpus-Based Studies of New Englishes. Amsterdam: John Benjamins, 243-262.

Mukherjee, Joybrato and Stefan Th. Gries. 2009. Collostructional nativisation in new Englishes: Verb-construction associations in the International Corpus of English. English World-Wide 30(1): 27-51.

Mukherjee, Joybrato and Marianne Hundt, eds. 2011. Exploring SecondLanguage Varieties of English and Learner Englishes: Bridging a Paradigm Gap. Amsterdam: John Benjamins.

Mukherjee, Joybrato and Schilk, Marco. 2012. Exploring variation and change in New Englishes: Looking into the International Corpus of English (ICE) and beyond. In Terttu Nevalainen and Elizabeth Closs Traugott, eds. The Oxford Handbook of the History of English. Oxford: Oxford University Press, 189-199.

Nelson, Gerald, Sean Wallis and Bas Aarts. 2002. Exploring Natural Language: Working with the British Component of the International Corpus of English. Amsterdam: John Benjamins. 
Parviainen, Hanna. 2016. The invariant tag isn't it in Asian Englishes. World Englishes 35(1): 98-117.

Peters, Pam. 2009. Irregular verbs. Regularization and ongoing variability. In Pam Peters, Peter Collins and Adam Smith, eds. Comparative Studies in Australian and New Zealand English. Grammar and Beyond. Amsterdam: John Benjamins, 13-29.

Rosenfelder, Ingrid. 2009. Rhoticity in educated Jamaican English: An analysis of the spoken component of ICE-Jamaica. In Thomas Hoffmann and Lucia Siebers, eds. World Englishes - Problems, Properties and Prospects. Amsterdam: John Benjamins, 61-82.

Sand, Andrea. 1999. Linguistic Variation in Jamaica - A Corpus-Based Study of Radio and Newspaper Usage. Tübingen: Narr.

Schneider, Edgar W. 2003. The dynamics of New Englishes: From identity construction to dialect birth. Language 79(2): 233-281.

Schneider, Edgar W. 2004. How to trace structural nativization: Particle verbs in World Englishes. World Englishes 23(2): 227-249.

Schneider, Edgar W. 2007. Postcolonial Englishes: Varieties around the World. Cambridge: Cambridge University Press.

Schneider, Gerold. 2008. Hybrid long-distance functional dependency parsing. Unpublished doctoral dissertation. www.zora.uzh.ch/id/eprint/ 7188/;

Schneider, Gerold and Marianne Hundt. 2009. Using a parser as a heuristic tool for the description of New Englishes. Paper presented at the Fifth Corpus Linguistics Conference, Liverpool, UK, July 20-23.

Schneider, Gerold and Marianne Hundt. 2012. "Off with their heads": Profiling TAM in ICE corpora. In Marianne Hundt and Ulrike Gut, eds. Mapping Unity and Diversity World-Wide: Corpus-Based Studies of New Englishes. Amsterdam: John Benjamins, 1-34.

Schneider, Gerold, Marianne Hundt and Daniel Schreier. 2019. Pluralized non-count nouns across Englishes: A corpus-linguistic approach to variety types. Corpus Linguistics and Linguistic Theory. doi:10.1515/cllt-20180068

Schütze, Carson T. 1995. PP attachment and argumenthood. MIT Working Papers in Linguistics 26: 95-151.

Sharma, Devyani. 2017. World Englishes and sociolinguistic theory. In Markku Filppula, Juhani Klemola and Devyani Sharma, eds. The Oxford Handbook of World Englishes. Oxford: Oxford University Press, 232-251.

Sigley, Robert and Janet Holmes. 2002. Looking at girls in corpora of English. Journal of English Linguistics 30(2): 138-157.

Szmrecsanyi, Benedikt. 2009. Typological parameters of intralingual variability: Grammatical analyticity versus syntheticity in varieties of English. Language Variation and Change 21: 319-353.

Szmrecsanyi, Benedikt and Bernd Kortmann. 2011. Typological profiling. Learner English versus indigenized L2 varieties of English. In Joybrato Mukherjee and Marianne Hundt, eds. 2011. Exploring Second- 
Language Varieties of English and Learner Englishes: Bridging a Paradigm Gap. Amsterdam: John Benjamins, 167-187.

Szmrecsanyi, Benedikt, Jason Grafmiller, Benedikt Heller and Melanie Röthlisberger. 2016. Around the world in three alternations: Modelling syntactic variation in varieties of English. English World-Wide 37(2): 109-137.

Tagliamonte, Sali A. and R. Harald Baayen. 2012. Models, forests, and trees of York English: Was/were variation as a case study for statistical practice. Language Variation and Change 24(2): 135-178.

Unuabonah, Foluke Olayinka and Ulrike Gut. 2018. Commentary pragmatic markers in Nigerian English. English World-Wide 39(2): 190-213.

Van der Auwera, Johan, Dirk Noël and Astrid de Wit. 2012. The diverging need (to)'s of Asian Englishes. In Marianne Hundt and Ulrike Gut, eds. Mapping Unity and Diversity World-Wide. Corpus-Based Studies of New Englishes. Amsterdam: John Benjamins, 55-75.

Vine, Bernadette. 2000. Getting things done: Some practical issues in a functional investigation of directives in spoken extracts from the New Zealand and British components of the International Corpus of English. In Christian Mair and Marianne Hundt, eds. Corpus Linguistics and Linguistic Theory. Amsterdam: Rodopi, 371-374.

Volk, Martin. 2001. Exploiting the WWW as corpus to resolve PP attachment ambiguities. In Paul Rayson, Andrew Wilson, Tony McEnery, Andrew Hardie and Shereen Khoja, eds. Proceedings of the Corpus Linguistics 2001 Conference, Lancaster, 30 March - 2 April 2001. Department of Linguistics. No pagination.

Wong, May L.Y. 2010. Expressions of gratitude by Hong Kong speakers of English: Research from the International Corpus of English in Hong Kong (ICE-HK). Journal of Pragmatics 42(5): 1243-1257.

Woods, Anthony, Paul Fletcher and Arthur Hughes. 1986. Statistics in Language Studies. Cambridge: Cambridge University Press.

Xiao, Richard. 2009. Multidimensional analysis and the study of World Englishes. World Englishes 28(4): 421-450.

Zipp, Lena. 2014. Educated Fiji English. Lexico-grammar and Variety Status. Amsterdam: John Benjamins. 